\title{
COVID 19 Lockdown - Air Quality Reflections in Indian Cities
}

\section{Aerosol and Air Quality} Research

Special Issue:

Special Issue on COVID-19 Aerosol Drivers, Impacts and Mitigation (XIII)

\section{OPEN ACCESS}

Received: June 19, 2020

Revised: January 2, 2021

Accepted: January 2, 2021

${ }^{*}$ Corresponding Author:

s_gulia@neeri.res.in

\section{Publisher:}

Taiwan Association for Aerosol Research

ISSN: $1680-8584$ print ISSN: 2071-1409 online

Cc) Copyright: The Author(s). This is an open access article distributed under the terms of the Creative Commons Attribution License (CC BY 4.0), which permits unrestricted use, distribution, and reproduction in any medium, provided the original author and source are cited.

\section{Sunil Gulia ${ }^{1}{ }^{*}$, Nitin Goyal ${ }^{2}$, Saurabh Mendiratta ${ }^{1}$, Tridipa Biswas ${ }^{1}$, S.K. Goyal ${ }^{1}$, Rakesh Kumar ${ }^{3}$}

${ }^{1}$ CSIR-National Environmental Engineering Research Institute, Delhi Zonal Centre, Naraina, New Delhi -110028, India

${ }^{2}$ CSIR-National Environmental Engineering Research Institute, Mumbai Zonal Centre, Worli, Mumbai - 400018, India

${ }^{3}$ CSIR-National Environmental Engineering Research Institute, Nehru Marg, Nagpur, 440020gpur 440020, India

\section{ABSTRACT}

The emergence of COVID-19 put pressure on the Governments of most of the countries in the world to enforce nationwide lockdown (restriction of all non-essential activities) to curtail the spread of infection. The nationwide lockdown created an adverse impact on the economies around the world and altered the day-to-day life of people. The restrictions on pollution generating activities during the lockdown period resulted in an overall improvement of the air quality throughout the world including India. This study evaluated the impact on air quality in 46 cities throughout India and the findings indicate that on average, $\mathrm{PM}_{2.5}$ and $\mathrm{NO}_{\mathrm{x}}$, concentrations reduced by about $34 \%$ and $60 \%$, respectively at different locations in India. $\mathrm{PM}_{2.5}$ concentrations reduced by about $23 \%, 16 \%, 32 \%$, and $28 \%$ in small, medium, large and megacities, respectively. However, the reduction in $\mathrm{NO}_{x}$ concentrations was dissimilar to $\mathrm{PM}_{2.5}$ in these cities. The findings further suggested that the impact of lockdown on air quality was not homogenous across the country and was probably due to varying background contributions. The average concentrations of $\mathrm{PM}_{2.5}$ and $\mathrm{NO}_{\mathrm{x}}$ at background stations were found higher in large and mega cities than the smaller cities. The $\mathrm{PM}_{2.5}$ concentrations at background stations were higher in North India in comparison to other parts of India.

Keywords: Restricted emission activities, Populated cities, Background concentrations, India, Lockdown

\section{INTRODUCTION}

The emergence of COVID-19 has placed the whole world on the brink of grave health risks. As of June 1,2020, the total reported confirmed cases were 6,057,853 including 371,166 deaths globally as per World Health Organization (WHO, 2020). COVID-19 has infected more than 200 countries worldwide including India and WHO had already declared COVID-19 as a pandemic on March 11, 2020. Most of the countries had implemented several strategies to prevent the disease from spreading. Social distancing and restricted movement were the major actions adopted by many countries including China, Italy, France, Spain, Philippines, Brazil, Singapore, India amongst others (Chen et al., 2020; Nakada and Urban, 2020, Venter et al., 2020).

The COVID-19 pandemic created unprecedented situations throughout the world and forced lockdown conditions in several countries. In India, efforts were made at local, regional, and national levels to restrict non-essential movement and contact amongst the human population to impede the spread of COVID-19. The government of India had declared nationwide lockdown from March 25, 2020, in a phased manner viz. Phase I from March 25 to April 14, Phase II from April 15 to May 3, Phase III from May 4 to 17, and Phase IV from May 18 to 31, 2020. The lockdown was 
enforced very effectively throughout the country wherein only essential services were kept operational and all other commercial, political, religious, educational, and entertainment activities amongst others were restricted. In Phase II, certain relaxations were extended to offices and agriculture activities (from April 20, 2020, onwards) and relaxations for several other services were extended strategically in Phase III and IV.

This countrywide lockdown situation restricted the Industrial production activities, all forms of transport (air, water, and land), hotels and restaurants, shopping malls, street eateries, tourism, construction and mining amongst others.

Though COVID-19 had severe adverse impacts on the economy throughout the world including India (Dev and Sengupta, 2020), it also brought a positive impact on air quality across the globe wherever lockdowns were implemented (Han et al., 2020; Isaifan et al., 2020; Nakada and Urban, 2020; Tobías et al., 2020; Xu et al., 2020). IEA (2020) has reported that the world experienced a sharp decline in carbon emissions between January and April 2020 compared to average levels in 2019 , and could decline anywhere between $4.4 \%$ to $8 \%$ by the end of this year. The coronavirustriggered lockdown has led to a steep fall in global carbon emissions by about $17 \%$ in early April as compared to 2019 levels with India's emissions dropping by about 26\% (Le Quéré et al., 2020).

Several Indian cities have been reporting poor levels of air quality in the past especially during post-monsoon and winter seasons (Gurjar and Nagpure, 2019; Guttikunda et al., 2019). The nationwide lockdown in India had reduced the air pollution load significantly in many cities and the atmospheric visibility had improved due to reduced levels of particulate matter. In the month of April, Dhauladhar mountain ranges of Himalayas were visible from Jalandhar (Punjab), and the Gangotri mountain ranges were visible from Saharanpur (Uttar Pradesh) which are about $200 \mathrm{~km}$ away (CNN, 2020; TOI, 2020). Researchers had reported reduced air pollution levels in selected Indian cities due to the nationwide lockdown (Jain and Sharma, 2020; Mahato et al., 2020; Mitra et al., 2020; Sharma et al., 2020). These studies were based on limited monitoring data and were restricted to megacities, however, there was a need to analyze the overall effect of lockdown throughout the Indian subcontinent.

The present study was undertaken to evaluate the impact of restricted activities due to lockdown on air quality in India. The present study analyses: $\mathrm{i})$ change in pollutant $\left(\mathrm{PM}_{2.5}\right.$ and $\mathrm{NO}_{\mathrm{x}}$ ) concentrations at 58 continuous ambient air quality station (CAAQMS) spread over 46 cities throughout India; ii) Zone-wise impact estimates i.e., for cities located in Northern, Eastern, Central, Western and Southern India and further differentiated based on the population of the city; iii) Categorization of all 58 stations into the background, residential/commercial and kerbside/industrial stations based on their site features; iv) Calculation of representative background values for selected pollutant concentrations in different regions of India.

\section{METHODOLOGY}

\subsection{Selection of CAAQMS and Study Period}

To evaluate the impact of restricted emission activities on air quality during the lockdown period in India, hourly average pollutant concentrations were collected from several continuous ambient air quality monitoring stations (CAAQMS) operated by Central Pollution Control Board (CPCB) and State Pollution Control Boards (SPCBs). The selection of CAAQMS was an important step in the present analysis and the criteria adopted were: i) availability of active CAAQMS (operating condition); ii) population of the city (Small $\leq 0.5$ million, Medium $=0.5-1.0$ million, Large $=1.0-5.0$ million and Mega $\geq 5.0$ million) and iii) Location of the city in India viz. North, East, Central, West, and South of India. Data were collected from 58 stations spread over 46 cities across India as listed in Table S1 of supplementary information (SI). The information of cities based on population and locations have been presented in Table 1. Out of the total 46 cities, 21 falls in North zone, 5 in East zone, 7 in Central zone, 6 in West zone, and 7 in the South zone. Number of CAAQMS stations are being operated higher in north zone compared to other zones of the country. Cities are more closer in northern zone which increase the possibility of intercity transboundary pollution contribution compared to other parts. The categorization of CAAQMS based on population was delineated as 15 in small, 9 in medium, 18 in large, and 5 in a mega-city. Out of 15 small cities, 9 are presented in North zone and 4 in central zone, similarly, out of 
Table 1. Classification of cities based on location and population.

\begin{tabular}{|c|c|c|c|c|c|}
\hline \multirow{3}{*}{ Size of City/Locations } & \multicolumn{5}{|c|}{ Nos. of City (Nos. of Stations) } \\
\hline & Small & Medium & Large & Mega & \multirow{2}{*}{ Total } \\
\hline & $>0.5$ million & 0.5-1.0 million & 1.0-5.0 million & $>5.0$ million & \\
\hline Centre & $4(4)$ & $1(1)$ & $2(2)$ & & $7(7)$ \\
\hline East & $1(1)$ & $2(2)$ & $2(3)$ & & $5(6)$ \\
\hline North & $9(9)$ & $2(2)$ & $9(9)$ & $1(7)$ & $21(27)$ \\
\hline South & & $3(3)$ & $2(2)$ & $2(5)$ & $7(10)$ \\
\hline West & $1(1)$ & $1(1)$ & $2(2)$ & $2(4)$ & $6(8)$ \\
\hline Total & $15(15)$ & $9(9)$ & $17(18)$ & $5(16)$ & $46(58)$ \\
\hline
\end{tabular}

17 large cities, 9 are in north zone and 2 in each other zone of country. Out of 5 megacities, 2 are located in west and south zone each and 1 in North zone.

The selection of the study period was another key parameter to accurately estimate the impact of restricted emission activities. The study period was selected in a way that both pre-lockdown (with source activities) and lockdown period (limited source activities) could be covered. The period from March 1 to 21, 2020, and March 25 to April 19, 2020, were selected to represent the pre-lockdown and Lockdown period, respectively. The period of March 22 to 24, 2020 was disregarded as only a few states had declared the lockdown, and these days were not a true representative of either pre-lockdown or lockdown period. The nationwide lockdown started from March 25, 2020, and continued until April 19, 2020, with full restrictions except for essential services. Conditional relaxations to operate offices and agricultural activities were extended from April 20, 2020, onwards.

Since the fate of air pollutants in the atmosphere is governed by the meteorological conditions, it was necessary to establish uniformity in meteorological parameters at all selected stations to compare the pre-lockdown and lockdown period. The average wind speed, relative humidity, and ambient temperature during pre-lockdown and lockdown periods and their differences were compiled, as shown in Fig. 1 and summarized in Table 2. It was observed that average wind speeds at all the selected stations were practically similar during both the periods, except at Panipat (Haryana) and Patiala (Punjab), where wind speed during lockdown was higher than prelockdown. The relative humidity in the Northern zone was slightly less during the lockdown period as compared to the pre-lockdown period at almost all the stations while ambient temperatures were found to be slightly higher during the lockdown period. Overall insignificant differences were observed in other parts of the country except for two stations in the Eastern and Central zone. The average wind speed increased by about $9.6 \%$ in the Northern zone; however, it decreased in the Western and Southern zone by about 3 to $5 \%$. The relative humidity decreased by about $28 \%$ in the Northern zone while it increased slightly in the Western zone from pre-lockdown to lockdown period. The ambient temperatures increased by about 16 to $22 \%$ in the Northern and Eastern zones. The differences in relative humidity and ambient temperatures during the two study periods in the Northern zone might influence the assessment of restricted activity on air quality due to lockdown, but there were insignificant changes in meteorology in other zones of India.

As lockdown was enforced throughout India, source activities in all directions from the stations were restricted homogenously, thus the impact of wind direction was considered to be negligible during these days. Thus, it was thus inferred that the difference between pollutant concentrations during pre-lockdown and lockdown period at the selected stations would be independent of the meteorological factors except for few stations in the north zone and would be impacted primarily by the reduction in emission load in the atmosphere due to restricted activities.

\subsection{Data Collection}

Real-time air quality monitoring across several cities in India by the deployment of CAAQMS has been underway for several years (CPCB, 2011). These stations were deployed for air quality assessment and management rather than for any statutory purpose. $\mathrm{PM}_{2.5}$ was monitored through Beta Attenuation Method (BAM)/Tapered Element Oscillating Microbalance (TEOM) while $\mathrm{NO}_{\mathrm{x}}$ was monitored through Gas-phase Chemi-luminescence method. The calibration, 


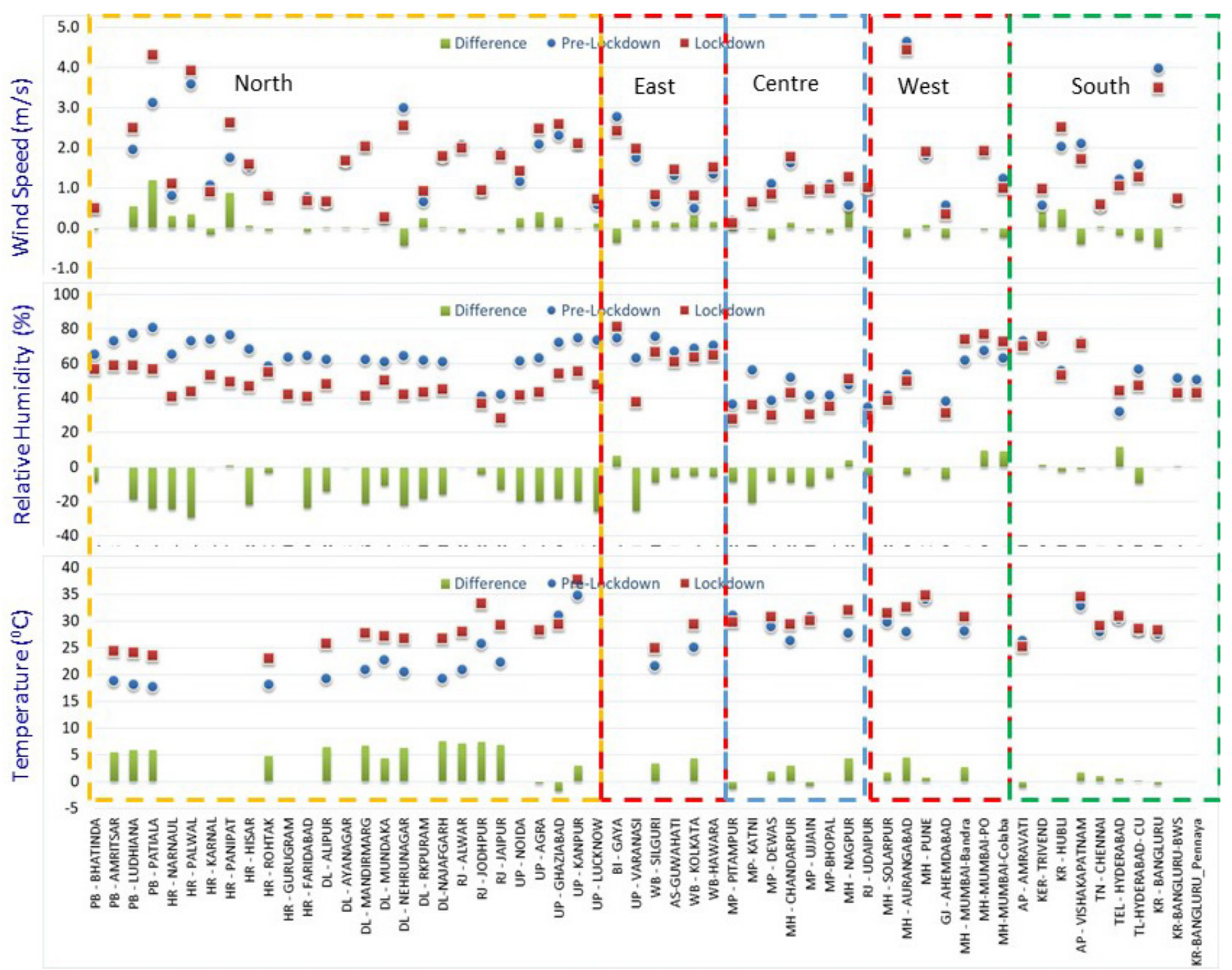

(PB: Punjab, HR: Haryana, DL: Delhi, RJ: Rajasthan, UP: Uttar Pradesh, BI: Bihar, WB: West Bengal, As: Assam, MP: Madhya Pradesh, MH: Maharastra, GJ: Gujrat, AP: Andra Pradesh, TEL: Telengana, KER: Kerala, KR: Karnataka, TN: Tamil Nadu)

Fig. 1. Change in meteorological parameters from pre-lockdown to lockdown period at selected Stations in India.

Table 2. Region-wise summary of differences in meteorological parameters during pre-lockdown and lockdown periods.

\begin{tabular}{|c|c|c|c|c|c|c|c|c|c|}
\hline \multirow[b]{2}{*}{ Regions/zones } & \multicolumn{3}{|c|}{ Wind Speed $\left(\mathrm{m} \mathrm{s}^{-1}\right)$} & \multicolumn{3}{|c|}{ Relative Humidity (\%) } & \multicolumn{3}{|c|}{ Ambient Temperature $\left({ }^{\circ} \mathrm{C}\right)$} \\
\hline & $\begin{array}{l}\frac{5}{3} \\
\frac{0}{0} \\
\frac{y}{0} \\
\frac{o}{d} \\
\frac{d}{2}\end{array}$ & $\begin{array}{l}\frac{5}{3} \\
\frac{0}{0} \\
\frac{v}{0} \\
0\end{array}$ &  & $\begin{array}{l}\frac{5}{3} \\
\frac{0}{0} \\
\frac{\text { o }}{0} \\
\frac{0}{d} \\
\frac{d}{2}\end{array}$ & $\begin{array}{l}\frac{5}{3} \\
\frac{0}{0} \\
\frac{0}{0} \\
0\end{array}$ & 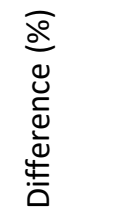 & $\begin{array}{l}\frac{1}{3} \\
\frac{0}{0} \\
\frac{u}{0} \\
0 \\
\dot{d} \\
\frac{d}{0}\end{array}$ & $\begin{array}{l}\frac{5}{3} \\
\frac{0}{0} \\
\frac{v}{0} \\
0\end{array}$ & 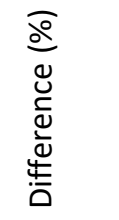 \\
\hline Northern & 1.56 & 1.71 & 9.64 & 65.61 & 47.11 & -28.20 & 22.57 & 27.63 & 22.40 \\
\hline Eastern & 1.39 & 1.50 & 7.66 & 69.87 & 62.45 & -10.61 & 23.28 & 27.16 & 16.66 \\
\hline Central & 0.89 & 0.94 & 5.34 & 44.69 & 36.06 & -19.32 & 28.97 & 30.42 & 5.01 \\
\hline Western & 1.86 & 1.77 & -5.25 & 51.45 & 53.14 & 3.28 & 29.96 & 32.40 & 8.12 \\
\hline Southern & 1.59 & 1.54 & -2.99 & 58.26 & 55.83 & -4.17 & 28.86 & 29.41 & 1.92 \\
\hline
\end{tabular}

operation, and maintenance of all stations were being carried out through the common guidelines issued by CPCB. Data were available in public domain on the website of CPCB (URL: https://app.cpcbccr.com/ccr/\#/caaqm-dashboard-all/caaqm-landing). These data on the portal 
get sourced directly from the continuous analyzers without scrutiny. The hourly average data of $\mathrm{PM}_{2.5}$ and $\mathrm{NO}_{x}$ were collected from the common portal and converted into the daily average for further analysis. The outliers from each data set were removed for both extreme lower and upper percentile values, which were seen to be out of the trend. The monitoring stations exhibited missing data for respective pollutant for few hours during the study period which might be due to long power cuts and maintenance (CPCB, 2020). The data for these missing hours were excluded from the statistical analysis.

\subsection{Data Analysis}

\subsubsection{Impact on air quality due to lockdown}

The city-wise and zone-wise impacts were calculated by comparing the pollutant concentration data of the pre-lockdown and lockdown period. The percentage difference was calculated by using Eq. (1).

$\Delta c=\frac{\left(C_{L}-C_{P L}\right) \times 100}{C_{P L}}$

where $\Delta c$ is the percentage change in concentration from Pre-lockdown to lockdown period, $C_{L}$ is the average pollutant concentrations during lockdown; $C_{P L}$ is the pollutant Concentration during Pre-lockdown period.

\subsubsection{Estimation of background concentration}

The study further attempts to estimate the background concentration by selecting the representativeness of each monitoring station. The background/baseline concentration has been defined as the pollution generating from the i) natural sources, ii) nearby sources other than the one currently considered and iii) unidentified sources. Generally, the background/baseline concentrations are required to predict incremental contributions from a source at a particular location. In the absence of source activities, average pollutant concentrations represent the contribution from natural sources, which can be treated as background/baseline concentration. In the Indian cities, another source to consider is the emission from cooking activities in residential areas, which is an essential activity for survival. Any such emissions would be a part of an urban background, which would vary as per the city's size (basically in terms of the population). It would further depend on the location of the CAAQMS in the city as the impact of emission from cooking will be reflected more when it is located in a residential area.

\section{RESULTS AND DISCUSSION}

\subsection{Impact on Air Quality during Lockdown Period in India}

\subsubsection{Zone-Wise}

The restriction on all non-essential activities during the lockdown period in India had resulted in significant impacts on air quality. The difference between average pollutant concentrations during pre-lockdown and lockdown period at all 58 monitoring stations were calculated, as presented in Fig. 2.

On an average, the difference in $\mathrm{PM}_{2.5}$ and $\mathrm{NO}_{x}$, concentrations were found to be about $-34 \%$ (52-34 $\mu \mathrm{g} \mathrm{m}^{-3}$ ) and $-49 \%\left(69-35 \mu \mathrm{g} \mathrm{m}^{-3}\right)$, respectively, in North zone, during lockdown period when compared to pre-lockdown period. The negative sign indicates a reduction due to the lockdown impact. The impact on both selected pollutants correlated well for most of the cities. In some of the cities, $\mathrm{NO}_{x}$ data were not available for the study period, so excluded from the analysis and only $\mathrm{PM}_{2.5}$ data were analyzed for these cities such as Rohtak, Narnual, and Faridabad in Haryana.

In the East Zone, the average difference in $\mathrm{PM}_{2.5}$ and $\mathrm{NO}_{x}$ concentrations were found to be about $-17 \%\left(66-54 \mu \mathrm{g} \mathrm{m}^{-3}\right)$ and $-57 \%\left(70-30 \mu \mathrm{g} \mathrm{m}^{-3}\right)$, respectively. The impact on $\mathrm{PM}_{2.5}$ and $\mathrm{NO}_{\mathrm{x}}$ were correlated well for most of the cities except Varanasi (UP) and Gaya (Bihar). The impact on $\mathrm{PM}_{2.5}$ was slightly less than $\mathrm{NO}_{\mathrm{x}}$ concentration, which might be due to variations in sources for both pollutants. 


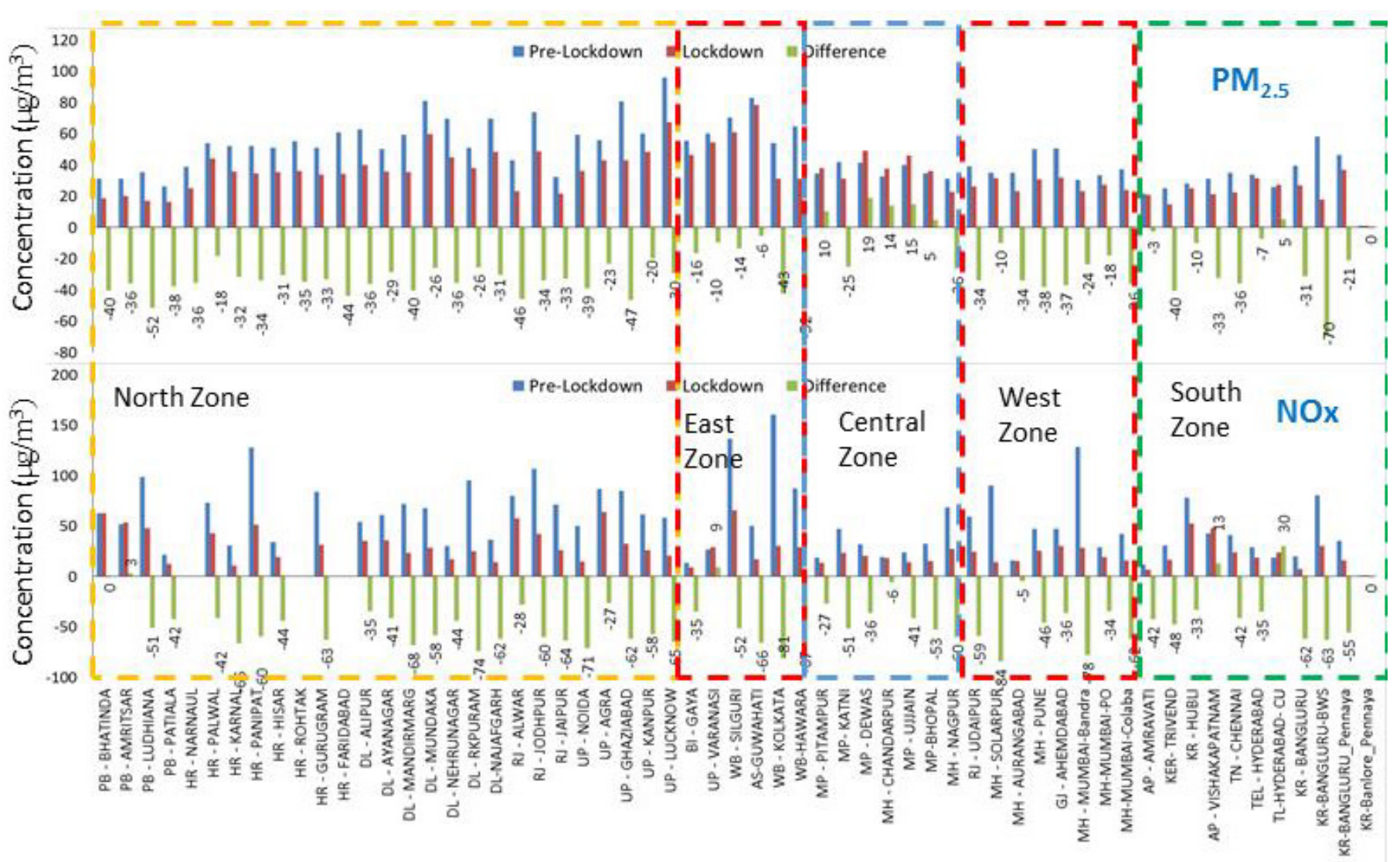

(PB: Punjab, HR: Haryana, DL: Delhi, RJ: Rajasthan, UP: Uttar Pradesh, BI: Bihar, WB: West Bengal, As: Assam, MP: Madhya Pradesh, MH: Maharastra, GJ: Gujrat, AP: Andra Pradesh, TEL: Telengana, KER: Kerala, KR: Karnataka, TN: Tamil Nadu)

Fig. 2. Change in average ambient concentrations in $\mathrm{PM}_{2.5}$ and $\mathrm{NO}_{\mathrm{x}}$ during lockdown compared to pre-lockdown periods in different cities of India.

The average difference in $\mathrm{PM}_{2.5}$ and $\mathrm{NO}_{\mathrm{x}}$, concentrations were found to be $1.7 \%(36.5-$ $37.2 \mu \mathrm{g} \mathrm{m}^{-3}$ ) and $-46 \%\left(35-19 \mu \mathrm{g} \mathrm{m}^{-3}\right.$ ), respectively, in the Central zone. The average $\mathrm{PM}_{2.5}$ concentrations in this region exhibited an increase of $1.7 \%$ instead of a decrease except for Nagpur (Maharashtra), which shows a $26 \%$ decrease. However, a significant reduction in $\mathrm{NO}_{\mathrm{x}}$ concentrations indicates the impact of restricted activities, which were not reflected in $\mathrm{PM}_{2.5}$ indicating the dominance of different background sources of $\mathrm{PM}_{2.5}$ in this zone compared to other zones.

The impact in the West zone was found to be significant with $-31 \%$ ( 41 to $28 \mu \mathrm{g} \mathrm{m}^{-3}$ ) and $-60 \%\left(54-22 \mu \mathrm{g} \mathrm{m}^{-3}\right)$ for $\mathrm{PM}_{2.5}$ and $\mathrm{NO}_{\mathrm{x}}$, respectively. However, in the South Zone, the impacts were $-26 \%\left(31-23 \mu \mathrm{g} \mathrm{m}^{-3}\right)$, and $-32 \%\left(39-27 \mu \mathrm{g} \mathrm{m}^{-3}\right)$, for $\mathrm{PM}_{2.5}$ and $\mathrm{NO}_{\mathrm{x}}$, respectively.

On an average, the $\mathrm{PM}_{2.5}$ reduced by $\sim 34 \%, \sim 17 \%, \sim 31 \%$, and $\sim 26 \%$ in North, East, West, and South zone, respectively, and increase of $1.7 \%$ in Central zone. Similarly, the $\mathrm{NO}_{\mathrm{x}}$ reduced by $\sim 49 \%, \sim 57 \%, \sim 46 \%, \sim 60 \%$, and $\sim 32 \%$ in North, East, Central, West, and South zone in selected Indian cities as presented in Table 3 . It could be inferred that the percentage reduction in $\mathrm{NO}_{\mathrm{x}}$ concentrations was higher than $\mathrm{PM}_{2.5}$ during lockdown periods throughout the country. The impact of lockdown was not homogenous throughout the country as natural contribution varies zone wise. In addition, some cities have industries related to essential services, which operated during this lockdown period and would have contributed to the pollution load of the city for a specific pollutant. The regional meteorology in different parts of the country plays an important role in the dispersion of pollutants resulting in variable impacts in different zones.

In order to visualize the results effectively, the percentage difference of $\mathrm{PM}_{2.5}$ and $\mathrm{NO}_{\mathrm{x}}$ at several monitoring stations in various zones were plotted using GIS application on the map of India as presented in Figs. 3 and 4, respectively. 
Table 3. Summary of the impact of lockdown on Air Quality in India.

\begin{tabular}{lllllll}
\hline \multirow{2}{*}{ Pollutant } & Parameters & \multicolumn{5}{c}{ \% Change in lockdown period in the Zone } \\
\cline { 3 - 7 } & & North & East & Centre & West & South \\
\hline PM $_{2.5}$ & Mean & -34 & -17 & 1.7 & -31 & -26 \\
& Maximum & -52 & -48 & -26 & -38 & -43 \\
$\mathrm{NO}_{\mathrm{x}}$ & Minimum & -16 & -6 & 19 & -10 & -2 \\
& Mean & -49 & -57 & -46 & -60 & -32 \\
& Maximum & -71 & -76 & -60 & -84 & -61 \\
\hline
\end{tabular}

Note: (-) negative sign indicates a reduction in concentrations.

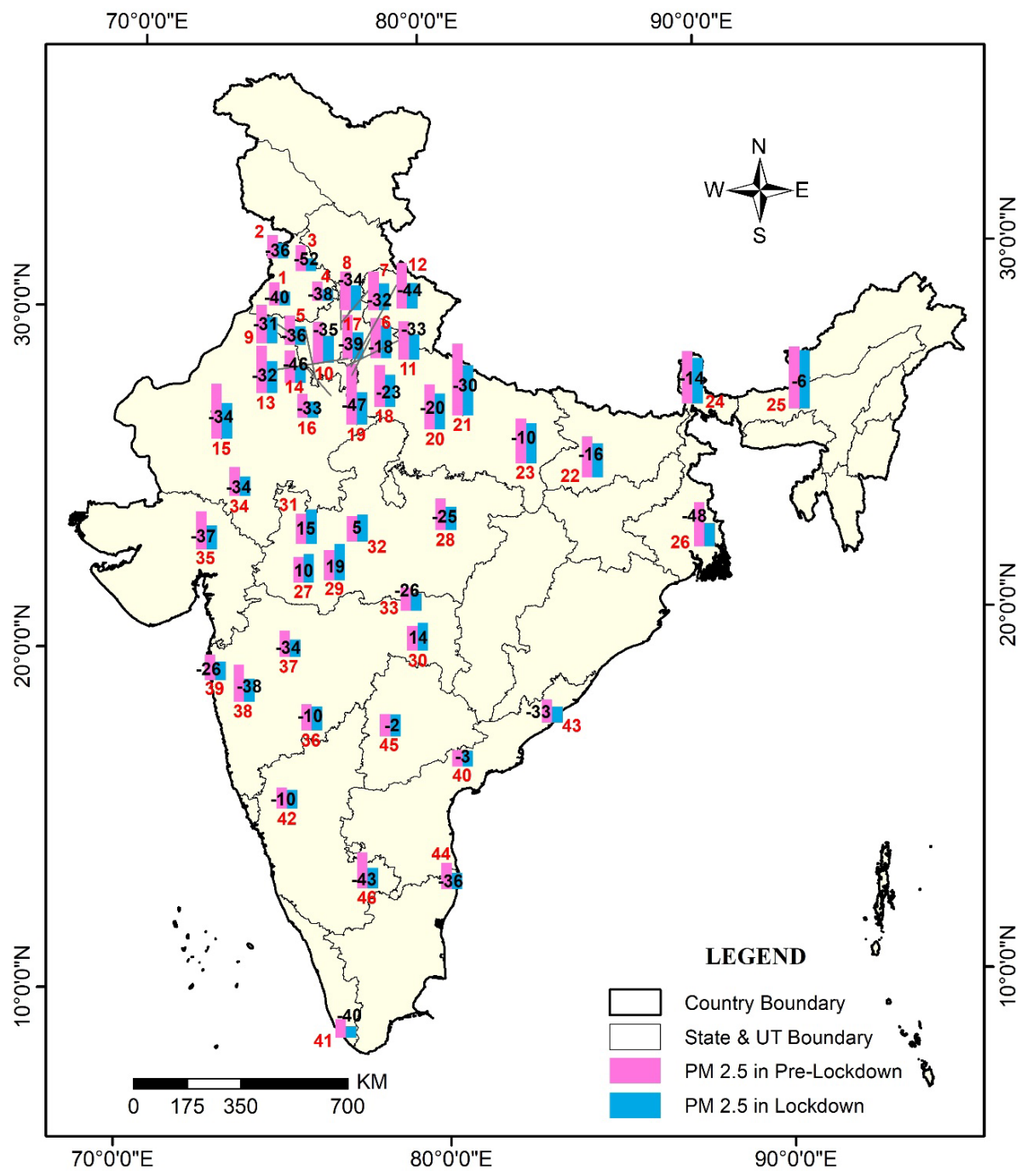

Fig. 3. Map showing CAAQMS locations and percentage difference in $\mathrm{PM}_{2.5}$ concentration from pre-lockdown to lockdown period at selected stations (Red colur values indicate stations serial number and black colour value shows percentage difference).

\subsubsection{Based on city population}

During the lockdown period, emissions from cooking activities in low-income residential sectors were a continuous source of pollution, which positively correlated with the population of the city. However, a reflection of these emissions only shows on CAAQMS, which were located in the residential area. Given the above, the cities were categorized based on population size as described in Table 1. 


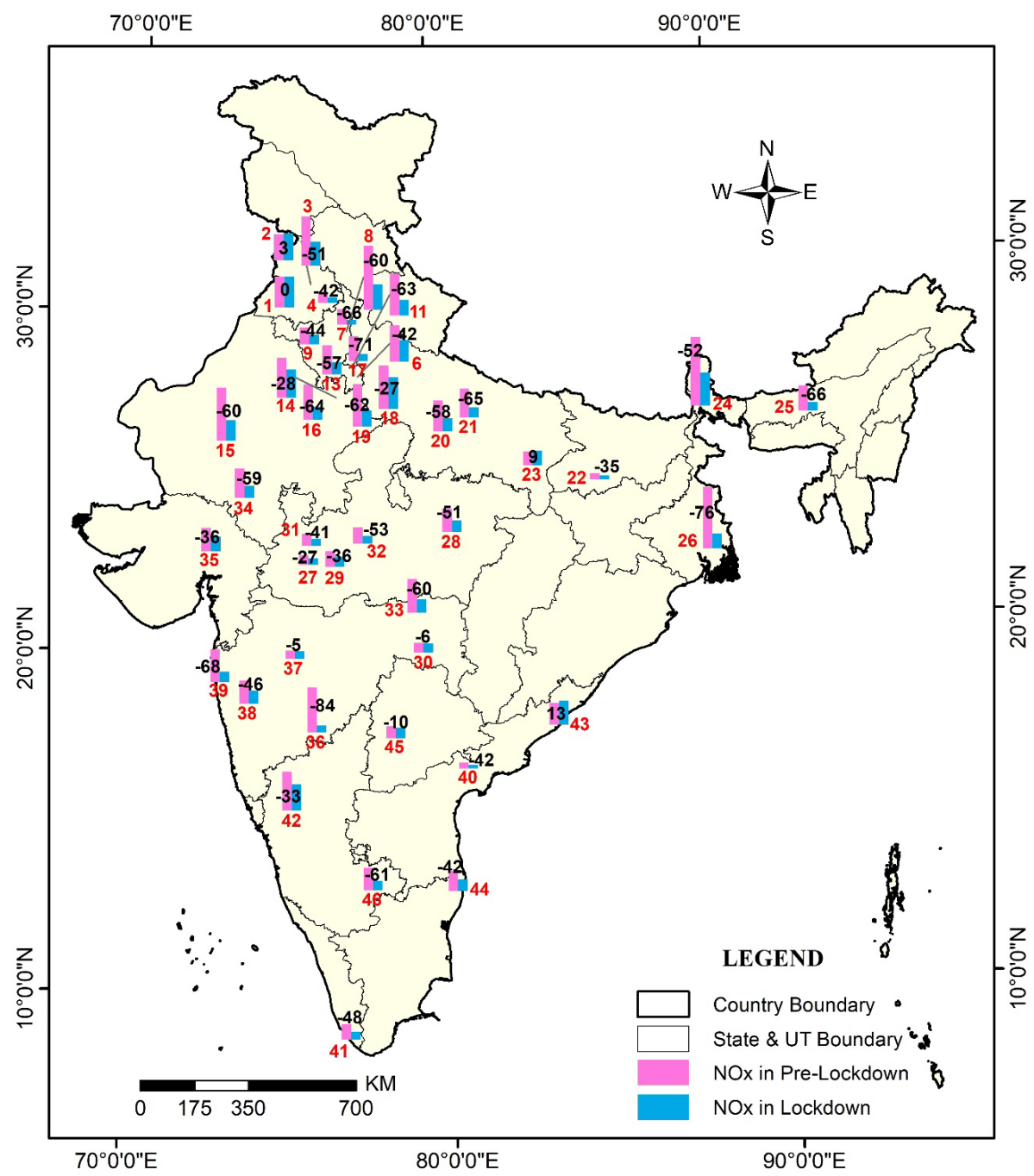

Fig. 4. Map showing CAAQMS locations and percentage difference in $\mathrm{NO}_{\mathrm{x}}$ concentration from pre-lockdown to lockdown period (Red colur values indicate stations serial number and black colour value shows percentage difference).

The average differences in $\mathrm{PM}_{2.5}$ and $\mathrm{NO}_{x}$ concentrations were found as $-23 \%$ and $-41 \%$, respectively, in small cities having a population $<0.5$ million as presented in Table 4 . In mediumsize cities, the impact was $-16 \%$ and $-56 \%$ for $\mathrm{PM}_{2.5}$ and $\mathrm{NO}_{\mathrm{x}}$, respectively. These differences in large cities were $-32 \%$ and $-42 \%$, respectively. The impact in mega-cities were significant with $-28 \%$ and $-46 \%$ for $\mathrm{PM}_{2.5}$ and $\mathrm{NO}_{\mathrm{x}}$, respectively. The $\mathrm{PM}_{2.5}$ concentrations reduced by $\sim 23 \%$, $\sim 16 \%, \sim 32 \%$, and $\sim 28 \%$ in small, medium, large, and mega-cities, respectively, indicating that large and mega-cities experienced higher impacts as compared to smaller cities. However, a similar pattern was not observed for $\mathrm{NO}_{\mathrm{x}}$. The major $\mathrm{PM}_{2.5}$ generating activities in large \& mega cities include Industrial emissions, vehicles movement, solid waste burning in open, operations of diesel generator (DG) sets in commercial areas, restaurants/hotels and street tandoors and their intensity of emission is higher in highly populated cities. All these sources were shutdown during lockdown as there was no demand except essential/emergency services and this reduction in activities/emission was reflected in higher reduction of $\mathrm{PM}_{2.5}$ concentration in large and mega cities. This is further supported through zone wise comparision of results of $\mathrm{PM}_{2.5}$ reduction as higher in North zone (maximum nine large cities). North Indian cities generally have higher particulate matter concentration compare to other region (AirVisual, 2018; Jain and Sharma, 2020). However, NOx reduction was found a maximum of $56 \%$ in medium scaled cities. The reductions in large \& mega cities are comparatively less (42-46\%) which might be due to higher per capita LPG consumption by domestic sector during the lockdown period which may 
Table 4. Impact of lockdown on air quality in small, medium, large and mega-cities in India.

\begin{tabular}{llllll}
\hline \multirow{2}{*}{ Pollutant } & Parameter & \multicolumn{4}{c}{ Change during the lockdown period in the cities (\%) } \\
\cline { 3 - 6 } & & Small & Medium & Large & Mega \\
\hline PM2.5 & Mean & -23 & -16 & -32 & -28 \\
& Maximum & -46 & -40 & -52 & -41 \\
NOx & Minimum & 19 & 15 & 5 & -2 \\
& Mean & -41 & -56 & -42 & -46 \\
& Maximum & -66 & -84 & -81 & -67 \\
& Minimum & -6 & -33 & 13 & -10 \\
\hline
\end{tabular}

limit higher emission from domestic sector and influence the overall $\mathrm{NO}_{\mathrm{x}}$ emission reduction at city levels.

\subsection{Estimation of Background Concentrations}

During the lockdown period, all the activities were restricted which generally contributes to the emissions in a city. Only activities related to essential services were allowed, however, their impact would be negligible in comparison to the overall emission load of the city. Though, certain stations recorded higher concentration during the lockdown period as compared to the prelockdown period, indicating the presence of sources in close vicinity. Hence, the location of a station is an important factor in order to estimate the background concentration of a city. Given the above, the location of each station was surveyed and studied using Google Earth and a comparative table was prepared. Based on the studied site features, these stations were categorized into three representative types viz. background, residential/commercial, and kerbside/industrial stations as presented in Table 5. The land-use features of all selected stations have been presented in SI Table S2. The background stations were those, which were located in open areas, where no sources were visible in the vicinity and the sites; generally surrounded by green areas and located towards the outskirts of the city. The residential/commercial stations were selected based on their vicinity to residential and commercial activities and located in the city center or populated areas. The kerbside /Industrial stations were marked along the edge of a major road i.e., National highway, State highway, and major city road and/or in an Industrial area.

Out of 58 stations, 13 were marked as background, 22 as residential/commercial, and 26 as kerbside/industrial stations. The average concentrations of $\mathrm{PM}_{2.5}$ and $\mathrm{NO}_{\mathrm{x}}$, at background stations, were $29(23-48) \mathrm{\mu g} \mathrm{m}^{-3}$ and $22(7-62) \mu \mathrm{g} \mathrm{m}^{-3}$, respectively. The average concentrations at residential stations for $\mathrm{PM}_{2.5}$ was $\sim 36(23-78) \mu \mathrm{g} \mathrm{m}^{-3}$ and $\mathrm{NO}_{\mathrm{x}} \sim 34$ (16-66) $\mu \mathrm{g} \mathrm{m}^{-3}$, respectively. At kerbside/industrial stations, the values were $\mathrm{PM}_{2.5} \sim 37(20-66) \mu \mathrm{g} \mathrm{m}^{-3}$ and $\mathrm{NO}_{\mathrm{x}} \sim 31$ (9-128) $\mu \mathrm{g} \mathrm{m}^{-3}$, respectively. The higher concentrations at residential/commercial areas clearly indicate the presence of urban sources during the lockdown period, which does not reflect at the background stations.

Further, Pearson correlations were estimated between pollutants to evaluate the impact of any common sources for each of the 13 background station category. The high positive correlation between pollutants indicates the presence of a source, which influences both the pollutants. No significant correlations were found between $\mathrm{PM}_{2.5}$ and $\mathrm{NO}_{x}$ at all stations as described in Table 5, except DL-Najafgarh i.e., 0.61. This station was not considered as representative background station.

The average concentration at selected 12 representative background stations during the lockdown period are presented in Table 6 . These may be well adopted as background concentration for these regions/cities for the summer season, which starts from the beginning of March month in India. The average concentrations of $\mathrm{PM}_{2.5}$ and $\mathrm{NO}_{\mathrm{x}}$ were $\sim 40 \mu \mathrm{g} \mathrm{m}^{-3}$ and $\sim 35 \mu \mathrm{g} \mathrm{m}^{-3}$ respectively, which were slightly higher than the background concentration of stations located in small cities surrounded by agriculture fields in North India viz. Narnaul, Hisar and Rohtak, all in Haryana. Similarly, in Central India, the CAAQMS in Nagpur represents background station and average concentrations were $\sim 23 \mu \mathrm{g} \mathrm{m}^{-3}$ and $\sim 27 \mu \mathrm{g} \mathrm{m}^{-3}$, for $\mathrm{PM}_{2.5}$ and $\mathrm{NO}_{\mathrm{x}}$, respectively. In Mumbai, two stations were selected as background stations, viz. Powai and Colaba. The average concentrations at these stations were found in the range of 24 to 27 and 9 to 16 for $\mathrm{PM}_{2.5}$ and $\mathrm{NO}_{\mathrm{x}}$ respectively. The 
Table 5. Classification of stations and average pollutant concentrations.

\begin{tabular}{|c|c|c|c|c|}
\hline $\begin{array}{l}\text { Classification of } \\
\text { CAAQMS }\end{array}$ & Site Feature & $\begin{array}{l}\text { Number of } \\
\text { Stations }\end{array}$ & $\begin{array}{l}\text { Kerbside/Traffic Site/ } \\
\text { Industrial zone/Residentia/ } \\
\text { Open Area }\end{array}$ & $\begin{array}{l}\text { Average \& Range } \\
\text { Concentration during } \\
\text { lockdown period } \\
\left(\text { Units: } \mu \mathrm{g} \mathrm{m}^{-3} \text { ) }\right.\end{array}$ \\
\hline Background Station & $\begin{array}{l}\text { CAAQMS located in an } \\
\text { open area, no direct } \\
\text { vicinity of any sources, } \\
\text { Site surrounded by } \\
\text { green area e.g., } \\
\text { building located in the } \\
\text { outskirt of the city }\end{array}$ & 13 & $\begin{array}{l}\text { No sources in the current } \\
\text { vicinity of the stations. Very } \\
\text { less possibility of transport } \\
\text { from distant sources. } \\
\text { Emission from the } \\
\text { scattered residential unit } \\
\text { can impact these CAAQMS, } \\
\text { but not significantly }\end{array}$ & $\begin{array}{l}\mathrm{PM}_{2.5}: 29(23-48) \\
\mathrm{NO}_{x}: 22(9-48)\end{array}$ \\
\hline Residential/Commercial & $\begin{array}{l}\text { Surrounded by residential } \\
\text { and commercial } \\
\text { activities }\end{array}$ & 20 & $\begin{array}{l}\text { Emission from populated } \\
\text { residential cooking. }\end{array}$ & $\begin{array}{l}\mathrm{PM}_{2.5}: 36(23-78) \\
\mathrm{NO}_{x}: 34(12-66)\end{array}$ \\
\hline Kerbside/Industrial & $\begin{array}{l}\text { Close to the major road } \\
\text { i.e., National Highway, } \\
\text { State Highway or major } \\
\text { city road. Located near } \\
\text { to Industrial area or } \\
\text { within industrial area }\end{array}$ & 25 & $\begin{array}{l}\text { Emission from vehicles used } \\
\text { for transport of essential } \\
\text { goods supply, emission } \\
\text { from industrial activities } \\
\text { related to essential services }\end{array}$ & $\begin{array}{l}\mathrm{PM}_{2.5}: 37(20-66) \\
\mathrm{NO}_{x}: 26(7-62)\end{array}$ \\
\hline Total & & 58 & & \\
\hline
\end{tabular}

Table 6. Average pollutant concentration at selected representative background stations and their contribution to NAAQS values.

\begin{tabular}{|c|c|c|c|c|c|c|}
\hline \multirow[t]{2}{*}{ Sr. No. } & \multirow[t]{2}{*}{ Cities/CAAQMS } & \multirow{2}{*}{$\begin{array}{l}\text { Correlation Coefficient } \\
\text { between } \mathrm{PM}_{2.5} \& \mathrm{NO}_{\mathrm{x}}\end{array}$} & \multicolumn{2}{|c|}{$\begin{array}{c}\text { Average Concentration } \\
\text { during lockdown }\left(\mu \mathrm{g} \mathrm{m}^{-3}\right)\end{array}$} & \multicolumn{2}{|c|}{ Percentage of NAAQS } \\
\hline & & & $\mathrm{PM}_{2.5}$ & $\mathrm{NO}_{\mathrm{x}}$ & $\mathrm{PM}_{2.5}$ & $\mathrm{NO}_{\mathrm{x}}$ \\
\hline 1 & HR - Narnaul & - & 25 & - & $42 \%$ & - \\
\hline 2 & HR - Hisar & 0.48 & 35 & 19 & $59 \%$ & $24 \%$ \\
\hline 3 & HR - Rohtak & - & 37 & - & $60 \%$ & - \\
\hline 4 & HR - Karnal & 0.43 & 36 & 10 & $60 \%$ & $13 \%$ \\
\hline 5 & PB - Ludhiana & -0.35 & 17 & 48 & $28 \%$ & $60 \%$ \\
\hline 6 & DL - Alipur & 0.52 & 40 & 35 & $67 \%$ & $44 \%$ \\
\hline 7 & MH - Nagpur & 0.42 & 23 & 27 & $38 \%$ & $34 \%$ \\
\hline 8 & MH-Mumbai-PO & 0.44 & 27 & 9 & $46 \%$ & $11 \%$ \\
\hline 9 & MH-Mumbai-Colaba & 0.52 & 24 & 12 & $40 \%$ & $15 \%$ \\
\hline 10 & AP - Amravati & 0.27 & 21 & 7 & $35 \%$ & $8 \%$ \\
\hline 11 & KER - Trivendram & 0.04 & 15 & 16 & $25 \%$ & $20 \%$ \\
\hline 12 & TL-Hyderabad & -0.06 & 27 & 47 & $45 \%$ & $59 \%$ \\
\hline
\end{tabular}

average concentration at background stations located in south India exhibits lower concentrations as compared to other selected stations. The average concentrations at Trivandrum in Kerala were $\sim 21 \mu \mathrm{g} \mathrm{m}^{-3}$ and $\sim 7 \mu \mathrm{g} \mathrm{m}^{-3}$, respectively for $\mathrm{PM}_{2.5}$ and $\mathrm{NO}_{\mathrm{x}}$.

The background concentrations were also analyzed to represent them as a percentage of 24hour NAAQS standard in India, as presented in Table 6. The 24-hour NAAQS value for PM2.5, and $\mathrm{NO}_{x}$, in India, were $60 \mu \mathrm{g} \mathrm{m}^{-3}$ and $80 \mu \mathrm{g} \mathrm{m}^{-3}$, respectively. The average background concentrations were found to be in the range of $25 \%$ to $67 \%$ of NAAQS for $\mathrm{PM}_{2.5}$, and $8 \%$ to $60 \%$ of NAAQS for $\mathrm{NO}_{\mathrm{x}}$.

\section{SUMMARY AND CONCLUSIONS}

The nationwide lockdown due to COVID-19 restricted most of the pollution generating 
activities throughout India. This study attempted to evaluate the impact of the lockdown on air quality in 46 cities spread across India. This study presents the analysis of air quality data for different zones in India viz. Northern, Eastern, Central, Western and Southern. In addition, citywise data were analyzed on the basis of small, medium, large, and mega-cities (the classification of cities was based on population). The salient findings of the studies are:

- In the Northern Zone, the difference in $\mathrm{PM}_{2.5}$ and $\mathrm{NO}_{\mathrm{x}}$, concentrations during the lockdown period as compared to the pre-lockdown period were found to be about $-34 \%\left(52-34 \mu \mathrm{g} \mathrm{m}^{-3}\right.$ ) and $-49 \%\left(69-35 \mu \mathrm{g} \mathrm{m}^{-3}\right.$ ), respectively. In the Eastern zone, these differences for $\mathrm{PM}_{2.5}$ and $\mathrm{NO}_{\mathrm{x}}$ concentrations were about $-17 \%\left(66-54 \mu \mathrm{g} \mathrm{m}^{-3}\right)$ and $-57 \%\left(70-30 \mu \mathrm{g} \mathrm{m}^{-3}\right)$, respectively. In the Central Zone, these were about 1.7\% (36.5-37.2 $\mu \mathrm{g} \mathrm{m}^{-3}$ ) and $-46 \%\left(35\right.$ to $\left.19 \mu \mathrm{g} \mathrm{m}^{-3}\right)$, respectively. The differences for $\mathrm{PM}_{2.5}$ and $\mathrm{NO}_{\mathrm{x}}$ concentrations were about $-31 \%\left(41-28 \mu \mathrm{g} \mathrm{m}^{-3}\right.$ ) and $-60 \%\left(54-22 \mu \mathrm{g} \mathrm{m}^{-3}\right)$, respectively in the western zone and $-26 \%\left(31-23 \mu \mathrm{g} \mathrm{m}^{-3}\right)$ and $-26 \%\left(39-27 \mu \mathrm{g} \mathrm{m}^{-3}\right.$ ), respectively in Southern zone.

- $\quad$ Based on population of cities, the average differences in $\mathrm{PM}_{2.5}$ and $\mathrm{NO}_{x}$ concentrations were found as $-23 \%$ and $-41 \%$, respectively, in small cities, $-16 \%$ and $-56 \%$ for $\mathrm{PM}_{2.5}$ in medium cities, $-32 \%$ and $-42 \%$, in large cities and $-28 \%$ and $-46 \%$ in mega cities.

- The average $\mathrm{PM}_{2.5}$ concentrations during lockdown period at remote (representative of background) stations were higher in North India $\left(17-40 \mu \mathrm{g} \mathrm{m}^{-3}\right.$ ) compared to the other parts (15-27 $\mu \mathrm{g} \mathrm{m}^{-3}$ ) of India. Similarly, for $\mathrm{NO}_{\mathrm{x}}$, the ranges were $10-48 \mu \mathrm{g} \mathrm{m}^{-3}$ at CAAQMS located in Northern India and 9-27 $\mu \mathrm{g} \mathrm{m}^{-3}$ at other parts of India except Hyderabad $\left(47 \mu \mathrm{g} \mathrm{m}^{-3}\right)$. Higher level of pollutant concentration in northern region might be due to presence of many high density populated cities in the regions and located in the same wind sector. Along with this, unfavaorable meteorological condition and geographical features may also be responsible for the higher concentration in northern area.

- The study also provides representative background concentrations for selected stations (representing area) in India that were not available so far and would find a use for air pollution-related studies in future in that particular city.

- The findings of the study indicate that proportion of average PM2.5 concentrations was in the range of $25-60 \%$ of specificied standard $\left(60 \mu \mathrm{g} \mathrm{m}^{-3}\right)$ at representraive background stations where these values for $\mathrm{NO}_{x}$ were $8-60 \%$ of specified standard $\left(80 \mu \mathrm{g} \mathrm{m}^{-3}\right)$. These findings provide a database for the policymaker to think about the need of revision of exisiting national ambient air quality standards, 2009.

- The findings further indicate that there may be an array of sources in each city and undertaking source apportionment studies for a better understanding of sources and their relative contributions to the air quality would be required to help the policymakers to decide on formulating the control strategies in future.

\section{ADDITIONAL INFORMATION}

\section{Declaration of Competing for Interest}

The authors declare that there are no financial and personal interests to influence the results and work presented in the manuscript.

\section{Author Statement}

Sunil Gulia: Concept, Methodology, Data Analyses, and writing the original manuscript. Nitin Goyal: Review and re-writing, Saurabh Mendiratta: Data Collation and Data preparation, Tridipa Bishwas: Bar chart plotting on India Map using GIS; S.K. Goyal: Review and Re-writing, Rakesh Kumar: Conceptualization.

\section{ACKNOWLEDGMENT}

The authors would like to thank the Central Pollution Control Board and State Pollution Control Boards for ambient air quality data of continuous ambient air quality stations used in the study. 


\section{SUPPLEMENTARY MATERIAL}

Supplementary data associated with this article can be found in the online version at https://doi.org/10.4209/aaqr.200308

\section{REFERENCES}

AirVisual (2018). 2018 Worlds Air Quality report. Region and city PM 2.5 ranking. https://www.iqair.com/us/world-most-polluted-cities

Chen, K., Wang, M., Huang, C., Kinney, P.L., Anastas, P.T. (2020). Air pollution reduction and mortality benefit during the COVID-19 outbreak in China. Lancet Planet. Health 4, E210-E212. https://doi.org/10.1016/S2542-5196(20)30107-8

CNN (2020). People in India can see the Himalayas for the first time in 'decades,' as the lockdown eases air pollution. https://edition.cnn.com/travel/article/himalayas-visible-lockdown-indiascli-intl/index.html

Central Pollution Control Board (CPCB) (2020). Limitation of CAAQMS data for AQI calc ulation. https://cpcb.nic.in/displaypdf.php?id=bmF0aW9uYWwtYWlyLXF1YWxpdHktaW5kZX gvTGItaXRhdGIvbnMucGRm (accessed 23 May 2020).

Dev, S.M., Sengupta, R. (2020). COVID-19: Impact on the Indian economy Indira Gandhi Institute of Development Research, Mumbai Working Papers 2020-013. https://ideas.repec.org/p/ind/i giwpp/2020-013.html

Gurjar, B.R., Nagpure, A.S. (2019). Indian megacities as localities of environmental vulnerability from air quality perspective. J. Smart Cities 1, 15-30. https://www.udspub.com/ajj/public/inde x.php/jsc/article/view/57/0

Guttikunda, S.K., Nishadh, K.A., Jawahar, P. (2019). Air pollution knowledge assessments (APnA) for 20 Indian cities. Urban Clim. 27, 124-141. https://doi.org/10.1016/j.uclim.2018.11.005

Han, Y., Lam, J.C., Li, V.O., Guo, P., Zhang, Q., Wang, A., Crowcroft, J., Wang, S., Fu, J., Gilani, Z., Downey, J. (2020). The Effects of Outdoor Air Pollution Concentrations and Lockdowns on COVID-19 Infections in Wuhan and Other Provincial Capitals in China. Preprints 2020, 2020030364 https://doi.org/10.20944/preprints202003.0364.v1

International Energy Agency (IEA) (2020). Global Energy Review 2020. IEA, Paris. https://www.iea. org/reports/global-energy-review-2020

Isaifan, R.J. (2020). The dramatic impact of Coronavirus outbreak on air quality: Has it saved as much as it has killed so far? Global J. Environ. Sci. Manage. 6, 275-288. https://doi.org/10.220 34/gjesm.2020.03.01

Jain, S., Sharma, T. (2020). Social and travel lockdown impact considering coronavirus disease (COVID-19) on air quality in megacities of India: Present benefits, future challenges and way forward. Aerosol Air Qual. Res. 20, 1222-1236. https://doi.org/10.4209/aaqr.2020.04.0171

Le Quéré, C., Jackson, R.B., Jones, M.W., Smith, A.J.P., Abernethy, S., Andrew, R.M., De-Gol, A.J., Willis, D.R., Shan, Y., Canadell, J.G., Friedlingstein, P., Creutzig, F., Peters, G.P. (2020). Temporary reduction in daily global $\mathrm{CO}_{2}$ emissions during the COVID-19 forced confinement. Nat. Clim. Change 10, 647-653. https://doi.org/10.1038/s41558-020-0797-x

Mahato, S., Pal, S., Ghosh, K.G. (2020). Effect of lockdown amid COVID-19 pandemic on air quality of the megacity Delhi, India. Sci. Total Environ. 730, 139086. https://doi.org/10.1016/j.scitote nv.2020.139086

Mitra, A., Ray Chadhuri, T., Mitra, A., Pramanick P., Zaman, S. (2020). Impact of COVID-19 related shutdown on atmospheric carbon dioxide level in the city of Kolkata. Parana J. Sci. Edu. 6, 8492. https://doi.org/10.5281/zenodo.3779156

Nakada, L.Y.K., Urban, R.C. (2020). COVID-19 pandemic: Impacts on the air quality during the partial lockdown in São Paulo state, Brazil. Sci. Total Environ. 730, 139087. https://doi.org/10. 1016/j.scitotenv.2020.139087

Sharma, S., Zhang, M., Gao, J., Zhang, H., Kota, S.H. (2020). Effect of restricted emissions during COVID-19 on air quality in India. Sci. Total Environ. 728, 138878. https://doi.org/10.1016/j.scit otenv.2020.138878

Times of India (TOI) (2020). Saharanpur wakes up to Himalayas, visible from town after 30. 
https://timesofindia.indiatimes.com/city/meerut/saharanpur-wakes-up-to-himalayas-visiblefrom-town-after-30-years-as-aqi-dips-below-50/articleshow/75465589.cms?utm_source=con tentof+interest\&utm_medium=text\&utm_campaign=cppst

Tobías, A., Carnerero, C., Reche, C., Massagué, J., Via, M., Minguillón, M.C., Querol, X. (2020). Changes in air quality during the lockdown in Barcelona (Spain) one month into the SARS-CoV2 epidemic. Sci. Total Environ. 726, 138540. https://doi.org/10.1016/j.scitotenv.2020.138540 Venter, Z.S., Aunan, K., Chowdhury, S., Lelieveld, J. (2020). COVID-19 lockdowns cause global air pollution declines. PNAS 117, 18984-18990. https://doi.org/10.1073/pnas.2006853117

World Health Organization (WHO) (2020). WHO Coronavirus Disease (COVID-19) Dashboard updated on 2020/06/01, 10:44pm CEST. https://covid19.who.int/

Xu K., Cui, K., Young, L.H., Wang, Y.F., Hsieh, Y.K., Wan, S., Zhang, J. (2020). Air quality index, indicatory air pollutants and impact of COVID-19 event on the air quality near central China. Aerosol Air Qual. Res. 20, 1204-1221. https://doi.org/10.4209/aaqr.2020.04.0139 